\title{
Oneirophrenia in dementia: when the difference between dream and reality becomes clouded
}

Keywords: oneirophrenia, dementia, sleep, dream, aids dementia complex

\section{Opinion}

The term 'Oneirophrenia' describes a state where a person becomes confused about the distinction between reality and dream as if he or she were living in a dream state. ${ }^{1}$ The Oxford Dictionary of Psychology defines oneirophrenia a 'dreamlike state of consciousness. ${ }^{2}$ ' More operationally, the ability to assess reality as such and to make a clear distinction of it from a dream or sleep requires a fully functional brain, the absence of substances affecting consciousness, and the lack of confusional states. According to the authors of the current article, when this ability is deficient, oneirophrenia ensues. Furthermore, oneirophrenia can become a chronic condition, like the one observed in dementia and can generate anxiety in patients who cannot adequately experience the reality as such. First observed in patients with AIDS Dementia Complex, ${ }^{3}$ oneirophrenia has also been found in other forms of dementia, like Alzheimer, and organic brain damage. However, oneirophrenia has also been described in patients with delirious mania and catatonia. ${ }^{4}$

Debatable opinions could support the pathogenesis of chronic oneirophrenia in patients with organic brain damage. The possible explanations are speculative as the observed dream-like state during the waking state can only be clarified according to a functional model. ${ }^{5}$ Hence, it is the opinion of the authors of the current article to theorize that during early and advanced dementia, the sleep-wake cycle can become clouded. Furthermore, in oneirophrenia, during the awakening or last stage of sleep, there is a 'laziness' of neuronal stimulation of the pontine centres by part of higher cortical structures. Accordingly, a person affected by dementia, not only has evident deficits in the alert state but also might have an under-stimulated pons and higher cortical structures due to the deficit of neurotransmitters or neuronal connections. As a consequence, some form of dream-sleep activity might persist beyond its physiological boundaries, that is, also when the patient is awake. Another working hypothesis takes into account the neuronal network system and the complex array of neuro-feedback mechanisms. Consequently, a person with an organic brain damage, with progressive loss of dendrite networks, is less able to utilize proper feedback from the world to make clear distinctions between dream, sleep, and reality. Additionally, the neuronal loops that inform the brain if the clues collected are from a subjective reality (like in a sleep-dream condition) or an objective one (real world) probably have a progressive loss in patients with dementia and clouding of consciousness. In this case, more complex and neuro-functional models should also be hypothesized to explain oneirophrenia in dementia. It is our opinion that a clear distinction between dream and reality only exists under the action of a coordinated and sophisticated neuro-feedback that continuously include into its loops the self, the objective world and the subjective-sleep reality. These feedback loops are necessary to inform our brain and cognition of what is real and what is not, of what is tangible and what, instead, is a pure sleepdream. ${ }^{6}$ Moreover, oneirophrenia can cause a certain degree of distress

\author{
Volume I Issue 5 - 2017
}

\author{
Carlo Lazzari, Ahmed Shoka, Basavaraja \\ Papanna, Georgios Mousailidis \\ Essex Partnership University Foundation Trust, UK
}

Correspondence: Carlo Lazzari, King's Wood Centre, Turner Rd, Colchester, CO4 5JY, UK, Email carlolazzari@nhs.net

Received: November 30, 2017 | Published: December 22, 2017

in patients with early dementia as they report that when interacting with others they cannot distinguish if they are dreaming during the interaction or if, instead, is all in their imagination. ${ }^{7}$ In conclusion, it is the opinion of the authors of the current article that during brain damage and dementia there is broken continuum between sleep and wake states inclusive of confusional states, delirium, twilight states, oneirophrenia, and catatonia.

\section{Conclusion}

The current research highlights the importance of functional neuro-feedback pathways as the underlying processes which make mind alert and aware of the difference between sleep, dream and wake state. During dementia, the decline of the neuronal network alters the activity of these feedback processes. The outcome is oneirophrenia, which, in the current article, is considered as a condition where a person is no longer able to make a convincing self-assessment if she or he is dreaming, sleeping, awake or not.

\section{Acknowledgements}

No funds were received by the authors for the current article. Observations and data were extracted by routine clinical practice while the presentation of findings to international congresses was self-funded.

\section{Conflict of interest}

The authors declare no conflict of interest for the current article.

\section{References}

1. Meduna LJ. Oneirophrenia: the confused state. Illinois, USA: University of Illinois Press; 1950.

2. Colman AM. A dictionary of psychology. 3rd ed. UK: Oxford University Press; 2014.

3. Lazzari C. Sleep disturbances and dream contents during brain atrophy in AIDS. $5^{\text {th }}$ International Congress for Infectious Diseases, Nairobi, Kenya; 1992.

4. Fink M, Taylor MA. The many varieties of catatonia. Eur Arch Psychiatry Clin Neurosci. 2001;251(Suppl 1):S8-13. 
5. Campione F, Lazzari C, Costigliola P, et al. Sleep disturbances and dream content during brain atrophy in AIDS. VIII International Conference on AIDS/III STD Congress, Netherlands; 1992.

6. Lazzari C. How the mind works. Lincoln, USA: IUniverse; 2007.
7. Lazzari C, Campione F, Costigliola P, et al. Dreams during brain atrophy in AIDS: A cybernetic-neurophysiological model. European Society for the Study of Cognition, special workshop Models of Cognitive Psychology, Leuven, Belgium; 1992. 